\title{
Practical and Theoretical Wisdom in Management Scholarship: Re-assesing the Use and Appropriations of Aristotle's Philosophy
}

\author{
Tuomo Peltonen ${ }^{1}$
}

Received: 28 January 2021 / Accepted: 1 July 2021/Published online: 19 July 2021

(C) The Author(s) 2021

\begin{abstract}
Within contemporary discussions on organizational wisdom, management scholars frequently turn to Aristotle's work to conceptualize wisdom as phronesis, or practical wisdom. Contrary to the prevailing view, this paper argues that Aristotle did not propose an exclusively practical or particularistic conception of wisdom but, instead acknowledged that wisdom broadly conceived consists of two types of intellectual virtue: theoretical wisdom (sophia) and practical wisdom. Aristotle's ultimate position regarding the relations between sophia and phronesis has remained, however, ambiguous, giving rise to different interpretations, and, more substantively, to the major appropriations of Aquinas, Heidegger and Gadamer. An analysis of the philosophical underpinnings of exemplary contributions to management wisdom suggests that research has predominantly applied Heideggerian and Gadamerian understandings of Aristotelian wisdom, while an Aquinian interpretation is largely absent in contemporary elaborations. Interpreting the Aristotelian notion of wisdom as dedicated purely to practical phronesis narrows the discussion on the nature of (organizational) wisdom within an Aristotelian framework in ways that do not give full credit to the breadth and complexity of Aristotle's thought.
\end{abstract}

Keywords Wisdom · Aristotle $\cdot$ Management $\cdot$ Philosophy

\section{Introduction: Aristotle, Phronesis and Wisdom in Management Studies and Philosophy}

Wisdom has been discussed extensively during recent years within organization and management theory, including contributions in special issues of scholarly journals (Nonaka et al. 2014; McKenna et al. 2013; McKenna et al. 2011), a major handbook (Kessler and Bailey 2007), as well as a steady outpouring of articles and books on the promise and challenge of

Tuomo Peltonen

Tuomo.peltonen@abo.fi; tuomo.t.peltonen@aalto.fi

1 Aalto University Business School, Espoo, Finland 
wisdom in organizing and managing (e.g. Yang 2011; Nonaka and Toyama 2007; Kuepers and Pauleen 2015; Shotter and Tsoukas 2014b).

Within the emergent discourse on managerial wisdom, the conception of practical wisdom, or phronesis, as articulated by Aristotle (2009), has received overwhelming attention among scholars debating the nature of wisdom in organizational contexts (Bachmann et al. 2018; Grint 2007; Schwartz 2011; Antonacopoulou 2010). A recent review identified over 40 theoretical papers published on phronesis in the field of administrative and organizational studies (Ames et al. 2020). Central to the conception of wisdom as phronesis is the presumption that phronesis differs both from theoretical knowledge and technical craft, involving instead a learned skill to distinguish the salient features of particular situations in a dialogue with ethical maxims (Grint 2007; Flyvbjerg 2006; Küpers and Statler 2008).

In particular, the distinction between practical and theoretical knowledge emerges as the crucial difference insofar as the adopted management philosophy is concerned. Theoretical wisdom, or sophia, is understood as the preference for universal metaphysical truths, set against phronesis emerging from the sensitivity to the immanent contexts of practice. For example, Flyvbjerg $(2004,289)$ notes that in the pursuit of practical wisdom, "[t]he particular and the situationally dependent are emphasized over the universal and over rules. The concrete and the practical are emphasized over the theoretical." Phronesis is conceptualized negatively, as something that excludes considerations of theoretical wisdom.

Contrary to the prevailing view, this paper argues that Aristotle (2009) did not propose an exclusively practical or particularistic conception of wisdom but, instead acknowledged that wisdom broadly conceived consists of two types of intellectual virtue: theoretical wisdom, or sophia, and practical wisdom, or phronesis. Further, it is claimed that in his discussion, Aristotle remains ambiguous as to whether he thinks that practical wisdom alone is sufficient to furnish prudent conduct, or whether theoretical wisdom should also be recognized as a complementary, or even primary, realm of wisdom. Aristotle's ambiguity has given rise to divergent interpretations regarding the constitution of wisdom in his oeuvre (e.g. Reeve 2013; Leibowitz 2013; Liu 2011). In any case, his exposition should be seen, minimally, as acknowledging the role of theoretical wisdom as a noteworthy aspect in any conceptualizations of wisdom.

Given the controversies and ambiguities inherent in Aristotle's own work, arriving at an authentic or authoritative interpretation of phronesis is complicated. Instead, it is argued that purportedly Aristotelian theories of wisdom tend to reflect a distinct reading or appropriation of Aristotle's original oeuvre. Apart from the divergent interpretations of Aristotle's original exposition, this paper identifies three historically influential appropriations that have aimed to develop or clarify the relationship between theoretical and practical wisdom. Of these, Aquinas (1920) affirms the duality of theoretical and practical wisdom and provides metaphysical depth to the conception of theoretical wisdom. Heidegger (1927), instead, largely excludes the role of theoretical wisdom in his appropriation of phronesis as practical coping in particularistic contexts. Gadamer (1960) follows Heidegger's practical emphasis but views phronesis as a dialogue between local and universal modes of interpretation and understanding.

To demonstrate the validity of the three different interpretations of theoretical and practical wisdom, the paper offers a secondary analysis of a set of impactful contributions to a phronetic theory of management wisdom. The chosen samples of management theory contributions are those of Flyvbjerg (2004), Shotter and Tsoukas (2014a, 2014b), and Nonaka and Toyama (2007). Each of the contributions is evaluated on the basis of the resonances of the particular conceptualization of wisdom with the interpretations of Aquinas, Heidegger and Gadamer. An 
analysis of the philosophical underpinnings of the understanding of wisdom suggests that scholars have predominantly applied Heideggerian and Gadamerian understandings of Aristotelian wisdom, while an Aquinian interpretation is largely absent in contemporary elaborations.

On a general level, the paper aims to offer a critical intervention to the ongoing discussions on managerial and organizational wisdom and its philosophical basis. The use of Aristotle as an authority in the conceptualizations of wisdom as practical phronesis can be challenged in light of the considerable ambiguity surrounding Aristotle's ultimate position regarding theoretical and practical wisdom. Aristotle's influential body of work can well be used to inform a host of issues in organizational scholarship (Hartman 2015), but any application of a major philosophical tradition like Aristotle's should remain sufficiently knowledgeable of the totality of the intellectual landscape of the philosophy in question (cf. Beadle 2002). In the case of wisdom, it might be argued that the intentions of the contributions advocating a particularistic conception of wisdom may not be best served by referencing primarily Aristotle's work. Instead, the theory of wisdom as phronesis as adopted in current discussions might find a more suitable philosophical sponsor from the projects of post-metaphysical thinkers like Heidegger or Gadamer.

This paper is structured so that the following section reviews the treatment of wisdom in Book VI of Aristotle's The Nicomachean Ethics and discusses the ambiguity of Aristotle's position as well as various interpretations of theoretical and practical wisdom. The subsequent part introduces the notable genealogical reworkings of Aristotle's oeuvre, namely the contributions of Aquinas, Heidegger and Gadamer. This is followed by an overview of the three examples of management theory contributions to Aristotelian wisdom. The fifth section then evaluates the three management theory samples against Aquinas's, Heidegger's and Gadamer's respective interpretations of wisdom. The final section offers general reflections regarding the different interpretations of the Aristotelian conception of management wisdom, especially concerning the relations between the theoretical and practical dimensions of wisdom.

\section{Aristotle's Engagement with Wisdom in The Nicomachean Ethics}

Aristotle develops his philosophy of wisdom primarily in Book VI of The Nicomachean Ethics (NE) (Aristotle 2009). Wisdom is discussed as a question concerning the intellectual virtues required for an agent to be able to mobilize and choose the relevant moral virtues in a thoughtful way. While moral virtues are predispositions of the lower, appetitive soul, virtues of thought are associated with the higher, rational soul. Aristotle frames his elucidation by defining the two parts that constitute the rational soul: "one by which we contemplate the kinds of things whose originative causes are invariable, and one by which we contemplate variable things" (NE 1139a, 7-9). The idea is to divide the rational part of the soul into two subsequent elements that are identified by their position in the hierarchy of the rational soul. The contemplative or scientific part represents the higher element that is capable of deliberating metaphysical truths, while the calculative part perceives reality in its varying actualities.

Aristotle then specifies the proper virtues of the two parts of the soul. The object of the higher, contemplative part is to reason about truth, most notably in the form of articulating universally valuable ends. The calculative or practical intellect, instead, is concerned with initiating movement towards good ends. The critical issue here is that "[i]ntellect itself... 
moves nothing, but only intellect which aims at an end and is practical" (NE 1139s, 35$1139 \mathrm{~b} 1)$. Therefore, the lower, calculative part of the rational soul is needed to mobilize desire towards good ends informed by the contemplative intellect.

Next, Aristotle delineates different forms of intellectual virtues. These are: scientific knowledge, intuitive reason, philosophical reason, art and practical wisdom. Scientific knowledge (episteme) is the search for the metaphysical first causes by way of induction and deduction. Craft or art (techne) on the other hand, involves the capacity to make things by way of bringing something into being. Practical wisdom (phronesis) is related to a reasoned capacity to act sensibly in the pursuit of the good (NE 1140b, 20-21). Intuitive reason (nous), in turn, is the unmediated sensing of the metaphysical first principles, conceptualized as a state of mind open to the transcendental truth. Finally, theoretical or philosophical wisdom (sophia) is defined by Aristotle as the combination of scientific knowledge and intuitive reason, or episteme and nous (NE 1141a, 18-19).

Of the intellectual virtues, scientific knowledge, intuitive reason and their amalgamation, theoretical wisdom, belong to the contemplative part of the rational soul. Craft and practical wisdom, instead, are virtues of the lower, deliberative part of the rational soul. Aristotle discusses each of these and concludes that craft or techne is not directly relevant for the focal examination, as it is concerned with making things, and thus not primarily involved with action (NE 1140a, 17-18), which is the principal domain of ethical and political inquiry. The remainder of Book VI discusses the relations between theoretical and practical wisdom that constitute the core elements of intellectual virtue.

Philosophical wisdom concerns the highest objects in reality, which are immaterial and eternal in nature. However, these highest objects of knowledge, echoing Plato's Forms, are not directly useful in judging what course of action to follow in immanent contexts. Here, practical knowledge appears to be the required counterpart to theoretical wisdom: "practical wisdom ... is concerned with things human, and things about which it is possible to deliberate" (NE $1141 \mathrm{~b}, 8-9$ ). Unlike the contemplation of the first principles characteristic of theoretical wisdom, practical wisdom is concerned not only with universals, but must also recognize the particulars (NE 1141b, 15-16).

In part three of Book VI, Aristotle delves into the specifics of practical wisdom, including what constitutes good deliberation, and how to evaluate the role of understanding and judgement in the performance of phronesis. Aristotle emphasizes that deliberation is concerned not only with means, but also with good ends. He also suggests that understanding is a component of phronesis, although it is by itself incapable of initiating action. Thirdly, Aristotle discusses judgement, and argues that judgement can be oriented both towards unchangeable universals as well as towards variable facts about a situation. While the correctness of perception, understanding and judgement is based on our human nature, it is with age and experience that these capabilities mature (NE 1143b, 9-13).

In the final part, Aristotle returns to the relation between theoretical to practical wisdom. After affirming that theoretical wisdom produces happiness solely by actualizing itself, the focus moves to practical wisdom. Aristotle emphasizes that practical wisdom is not mere cleverness, for a clever person might not have the well-developed moral virtues needed to guarantee that the means chosen are balanced and good. At the same time, he asserts that moral virtue makes the goal right and practical wisdom is therefore merely responsible for the correctness of the means. In any case, the conclusion is that practical wisdom is inherently intertwined with moral goodness (NE 1144a, 36-37). Practical wisdom is a disposition 
required for the good actualization of moral virtues, while at the same time its correct use is dependent on well-formed moral virtues (1144b, 30-32).

Towards the end of the section, Aristotle returns to the relations between the two types of wisdom. Here, practical wisdom is understood as not directly employing or using theoretical wisdom but providing "for its coming into being" (NE 1145a, 8). In his closing remarks, Aristotle again emphasizes that despite the prominent role given to practical deliberations, practical wisdom "is not supreme over philosophical wisdom" (original italics) (NE 1145a, 6).

Taken together, Aristotle's (2009) discussion seems to accentuate the provision that wisdom or intellectual virtue is composed of two elements but remains somewhat ambiguous regarding the relationship, primacy and interaction between theoretical and practical wisdom. What is clear is that he defines theoretical wisdom or sophia as the combination of scientific knowledge and intuitive reason. Theoretical wisdom thus conceived represents an awareness of the metaphysically prior prime movers associated with knowledge obtained from inductive reasoning. This is perhaps best understood as an intuitive sense of the metaphysical universals in their empirical manifestations, not an adherence to the general rules or laws governing ethical or political phenomena.

The relationship of theoretical knowledge to practical wisdom, however, remains more elusive. It is not fully clear whether Aristotle sees the two components of wisdom as separate spheres that operate at different levels of reality, or whether he is arguing that the two are mutually constitutive of the totality of wisdom. Furthermore, if he intends to include both theoretical and practical wisdom in his conception of intellectual virtue, the question arises whether they to be approached as equals or is one more prominent than the other.

The ambiguity of Aristotle's elucidation has given rise to different interpretations of his philosophy (Baehr 2012). There is a school that suggests that Aristotle was a particularist and that he advocated an ethical and political theory based on the dominance of practical wisdom in matters of social and political life. The context for this interpretation is the observation that the main argument of NE appears to be the denial of the role of universal moral rules in guaranteeing ethical conduct (Dancy 2004; McDowell 2014). Similarly, wisdom, as the province of intellectual virtues, can be seen as relying on the honing of the agent's character and the capacity to distinguish the salient features of contingent situations, rather than on the mastery of abstract reasoning (Leibowitz 2013). Insofar as immanent action is a separate domain from the sphere of theoretical knowledge or intuition, it makes sense to treat phronesis as largely independent of the philosophical contemplation that characterizes theoretical wisdom (Sorabji 1980; Natali 2014).

A second interpretation acknowledges the role of theoretical wisdom alongside that of phronesis and suggests that they together constitute the holistic totality of wisdom for Aristotle (Liu 2011). Wisdom requires the sort of deliberation about the critical features of a situation that can only be delivered by practical wisdom, but phronesis cannot accomplish this task on its own. Rather, theoretical wisdom is needed to clarify the good ends and to polish the perception of the morally crucial qualities in contingent events (Rorty 1978; Cooper 1969). Conversely, theoretical wisdom alone cannot guarantee prudent conduct in situations that remain ethically ambivalent or contradictory (Cammack 2013); therefore, practical wisdom is in most cases needed to find the correct means to pursue the esteemed ends.

The third way of understanding Aristotle's exposition is to assign prominence to theoretical wisdom (Nagel 1972). This strand of interpretation rests on the metaphysical structure of the human soul that Aristotle develops throughout NE and that culminates in Book X. As noted, Aristotle divides the rational soul into two parts, of which the higher part contemplates 
universal and necessary truths, and of which the lower part is focused on reasoning about the variable phenomena of social and political affairs. In Book X, Aristotle maintains that the philosophical contemplation characteristic of the higher part of the rational soul is the most complete form of human happiness (eudaimonia) (NE 1177b 16-26). Based on this view, it can be deduced that Aristotle intended theoretical wisdom to represent the best form of life and that practical wisdom could be understood as the second-best life, which is reserved for those that cannot yet reach the heights of metaphysical or spiritual contemplation (Cooper 1969; Baker 2017). Being the foremost type of wisdom, theoretical wisdom, as an intuitive grasp of first principles in their empirical emanations, can even be appreciated as having immediate practical applicability, especially in the hands of those who are advanced in philosophical intuition (Reeve 2013).

It is not possible to exhaustively explicate the various interpretations of theoretical and practical wisdom within the limitations of a single article. The existence of the debate, however, corroborates our argument that Aristotle's examination of wisdom lends itself towards differing appraisals with regard to the status of phronesis as the exclusive focus for a theory of wisdom. Consequently, it could be maintained that the particularistic conception of prudence equating wisdom with phronesis cannot be straightforwardly justified with reference to Aristotle's philosophy. Rather, wisdom understood exclusively as practical wisdom is to be better conceived of as a particular interpretation of Aristotle's examination of intellectual virtues that competes with alternative readings that recognize the role of theoretical wisdom in Aristotle's study. Instead of finding good reasons for a phronetic or other interpretation of wisdom in Aristotle's original work, it is in the later philosophical appropriations of Aristotle that distinct interpretations receive a more developed form usable as a philosophical framework. Three of the later appropriations can be evaluated as significant in the genealogy of Aristotelian thinking, and it is to those philosophies that we turn next.

\section{A Brief Genealogy of the Philosophical Appropriations of Aristotle's Conception of Wisdom: Aquinas, Heidegger and Gadamer}

In dissecting the potential backgrounds related to the differing interpretations of the implications of Aristotle's discussion on wisdom, we can distinguish at least two philosophical genealogies related to theoretical and practical wisdom. The first one, associated with Thomas Aquinas, represents a medieval re-reading of Aristotle's work from a scholastic and Neoplatonist perspective, while the elucidations of Heidegger and Gadamer provide a (post-)modern existential-hermeneutic reworking of Aristotle's original exposition.

Thomas Aquinas discusses wisdom or prudence extensively in his Summa Theologiae, especially in questions 47-56 (Aquinas 1920). Although his delineation of wisdom follows in many respects Aristotle's original articulation, it nevertheless clarifies or appropriates Aristotle's description of certain key issues in ways that make it a unique reworking of the original discussion. Essential for the present inquiry is the way in which Aquinas clarifies and deepens the role of theoretical or philosophical wisdom. For him, a fuller recognition of the theoretical dimension of wisdom demands metaphysical attention to the first principles conditioning the pursuit of sophia in Aristotle's scheme (Eh 2017). The universal aspects of wisdom emerge principally from natural reason that is sustained by the habit of intuiting the transcendental truth or participating in divine charity. Furthermore, though Aquinas supports the view of the duality of sophia and phronesis in the pursuit of wisdom, he assigns more 
weight to the role of universal principles in the ontological and epistemological dynamics of wisdom or prudence (Hoffmann 2013). Universal principles, attained with the help of natural reason, enable the human actors to see the good ends implicit in the myriad of practical potentialities.

Heidegger (1927), in contrast, reads Aristotle's phronesis as a more exclusive domain of attaining truth within the particularistic contexts of practical awareness (Thanassas 2012). He treats theoretical knowledge from a historicist standpoint, refusing to acknowledge the metaphysical properties of truth-seeking associated with the philosophical contemplation of the first principles as advocated by Aristotle and Aquinas. As a result, Heidegger's understanding of wisdom comes to revolve around the relationship of the self-reflective subject and her historically specific socio-cultural contexts. That is, the transcendental features of theoretical knowledge, and the associated requirement for the ultimate ends in the pursuit of phronesis, are replaced with a kind of personal reflection of one's self-knowledge and its limits (Long 2002Wisdom is treated as a purely practical phronesis, aimed at coping with the particularities of the here and now.

A similar reduction of sophia into a component of practical coping occurs in Gadamer's (1960) work. Under the influence of Heideggerian existential-phenomenological philosophy, Gadamer conceptualizes wisdom as a hermeneutical process or activity, where the practical particularities and the general horizons are juxtaposed in a dialogical process of an ongoing contrasting of totality-in-locality with locality-in-totality (Backman 2015). The relation between the universal and the particularistic aspects in the pursuit of wisdom occur in Gadamer's re-appropriation entirely within the meaning-creating processes of the hermeneutic circle. Interpretations of the current situations evolve into universalized pre-understandings, which are subsequently juxtaposed with the evolving local interpretations of unfolding events (Duvenage 2015). The role of theoretical or philosophical contemplation does not extend to the metaphysical realm, or being, but instead, is seen as a part of the constant process of revising and applying the evolving universal discourses in light of the unfolding readings of immanent situations.

To summarize, the three appropriations of Aristotelian philosophy of wisdom provide diverging views on the roles of sophia and phronesis in the pursuit of wisdom. Aquinas (1920) follows mainly a dualistic interpretation, albeit with a more metaphysically rigorous account of the type of theoretical wisdom required for intuiting the universal principles conditioning practical rationality. For Aquinas, phronetic judgement continues to be of importance for wisdom as enacted in action, but simultaneously, practical wisdom is ultimately relegated to a more instrumental role in the overall dynamics of prudence.

Instead, for Heidegger, phronesis alone represents the area of philosophically sound judgement, with sophia being largely separated from the deliberations of localized instances of practical wisdom. Practical engagement with the situated contexts of immediacy becomes fundamental here for the conception of wisdom (Thanassas 2012). Gadamer, on the other hand, fuses sophia and phronesis within the process of hermeneutic interpretation (Backman 2015). Universal pre-understanding is represented by the accumulated traditions of a cultural community, providing a normative horizon against which the local interpretations of the unfolding events are juxtaposed in the ongoing practice of dialogical meaning making. The universality of inherited traditions informs the framing of particular situations, while simultaneously, the particularity of each unique instance prompts an evaluation of the soundness of the inherited universal horizon. 
Compared to the different interpretations of Aristotle's original exposition, Aquinas' (1920) position is in principle consistent with a dualistic reading of theoretical and practical wisdom. His deepening of the metaphysical and spiritualistic properties of theoretical wisdom, however, shifts the understanding of prudence slightly in the direction of the primacy of theoretical contemplation. Heidegger (1927), instead, builds a conception that is similar to the particularistic reading by focusing exclusively on practical awareness within situated contexts. Gadamer (1960), on the other hand, seemingly endorses an interpretation reminiscent of the dualistic reading that pays attention to both theoretical and practical wisdom. His hermeneutic approach, however, reduces the scope of theoretical reason to the cultural pre-understandings inherent in the accumulated traditions, comprising thus a kind of post-metaphysical variant of the dualist interpretation.

\section{A Sample of Prominent Aristotelian Conceptions of Wisdom in Management Studies}

Having outlined the different interpretations and philosophical appropriations of Aristotle's original discussion of theoretical and practical wisdom, we turn next to the uses of Aristotle's work in management studies. The paper will discuss three prominent contributions to the theory of management wisdom, each leaning on Aristotle's work. These exemplars are not meant to represent an exhaustive coverage of the multitude of discussions on wisdom in management theory; rather, they are introduced as significant contributions that have explicitly mobilized Aristotle's oeuvre in relation to the emerging understanding of wisdom in organizational management. ${ }^{1}$ For our review, we have identified three influential contributions. Of these, Flyvbjerg's (2004) work crosses from planning research to organization theory, while Nonaka and Tayoma's (2007) and Shotter and Tsoukas' (2014a, 2014b) contributions are located more firmly in the focal field of management and organization studies. Nonaka and Tayoma (2007) deliberate on wisdom mainly in the context of strategic management, while Shotter and Tsoukas (2014a, 2014b) offer their articulations primarily to the debates on management learning and education. All three can, however, be considered paradigmatic cases of theoretical works advancing an Aristotelian conception of wisdom as phronesis in management theory.

Flyvbjerg (2004; cf. Flyvbjerg 2002; 2006) defends the idea of wisdom as phronesis, or practical wisdom, drawing explicitly from Aristotle's work. Flyvbjerg's (2004) phronetic paradigm of wisdom is oriented towards investigating ethical and political challenges and possibilities in concrete organizational cases. Generally speaking, he argues for a conception of wisdom that privileges the particular and the local over the abstract and the universal that are typically privileged in the conventional rationalistic approach to knowledge and decisionmaking. Consequently, of importance for Flyvbjerg (2004) is Aristotle's insistence on the skills, attitudes and virtues necessary to pursue wisdom practically in the immanent and shifting circumstances of organizational occurrences.

Flyvbjerg (2004) cites parts of NE to support his scrutiny of wisdom as phronesis. He, for example, quotes NE 1141b8-27, where Aristotle articulates the meaning of practical wisdom in relation to the nature of theoretical wisdom. According to Flyvbjerg, the citation

\footnotetext{
${ }^{1}$ The three contributions were selected based on their scientific impact as indicated by the highest numbers of Google Scholar citations.
} 
demonstrates the general conclusion that Aristotle is stressing the priority of concrete cases over general rules in wise conduct. More specifically, he contrasts Aristotle's elevation of particular situations with Plato's insistence on the primacy of transcendental forms. Flyvbjerg argues that the two offer diametrically opposed versions of the source of wisdom, with Plato prioritizing abstract theories that are deemed generally valid across contexts, and Aristotle accentuating the critical role of immanent practices and embedded means-ends-relations.

According to Flyvbjerg (2004), the apparent victory of Platonic universalism over Aristotelian particularism has left its mark on the legitimate pursuit of knowledge and understanding in contemporary thinking. Valid knowing is believed to emerge from the abstraction of local experiences instead of being generated within the immanent nexuses of situations, interests and values. However, as Flyvbjerg notes, phronetic alternatives to universalized ideas are nevertheless available in a multitude of domains. In management education, Flyvbjerg (Flyvbjerg 2004; 288) points out that the Harvard Business School tradition of teaching via case studies could be understood as more Aristotelian, in contrast to approaches to management studies that stress abstract theory and universal rules. Phronetic research would further develop the casebased thinking in generating actionable knowledge for wise decision-making.

Another influential conception of wisdom has been offered by Nonaka and Toyama (2007). They propose a conception of wisdom as phronesis in the context of strategic management. Nonaka and Toyama's approach leans on Aristotle's articulation, but appropriates Aristotle's philosophical work in a somewhat different fashion compared to Flyvbjerg's praxis-oriented reading. In the first instance, however, they seem to subscribe to a strictly particularistic emphasis of the nature of wisdom, by for example stating that "phronesis as political judgment is the ability to initiate action toward the future based on universal consensus about specific goals and measures reached through the shared judgment and conviction of individuals in each context" (Nonaka and Toyama 2007; 378). The emphasis is on finding the most appropriate way to initiate action based on collectively agreed good ends in each situation. The ideas of the common good are negotiated with the help of ethical convictions and value commitments of the community of practice involved.

Yet elsewhere in their paper, Nonaka and Toyama $(2007 ; 383)$ seem to give more latitude to the universal ideals in the quest for wisdom. They argue that the need to grasp the essence of the common good calls for an ability to synthesize general, universal knowledge with the particulars of the concrete situations. The search for goodness requires that the leader of the organization take part in the values of truth, goodness and beauty. Here, Nonaka and Toyama $(2007 ; 380)$ subscribe to an understanding of the good as a personal attribute achieved through participation in the metaphysical truths or moral ideals. In organizational contexts, this translates to value commitments that are primarily derived from the deep philosophical assumptions and ideals of the corporate culture.

As a result, Nonaka and Toyama (2007) portray the pursuit of wisdom as a dialectic between the universal truths and the salient features of particular situations. The methodology of attaining the metaphysical truth is at times presented in an Aristotelian manner as an inductive exercise of grasping the universals behind the particulars, and at times in a more Platonic manner as a deductive exercise of orientating oneself directly towards the otherworldly Forms underlying empirical reality. Yet, in general, their exposition seems to underline the role of transcendental universals alongside that of the particular features of practical contexts in the pursuit of organizational wisdom.

A third notable contribution has been delivered by Shotter and Tsoukas (2014a, 2014b). Their approach to phronesis is largely motivated by the critique of the latent rationalism 
inherent in the prevailing conceptualizations of managerial wisdom. As an alternative, Shotter and Tsoukas (2014a) present a performative understanding of wise judgement derived from Aristotelian phronesis. The authors in particular refer to Aristotle's argument that the goal of practical reason is to undertake ethically appropriate action in particular circumstances. It is thus the internal logic or world of practice that becomes the focus of reflective deliberation in the pursuit of organizational wisdom.

In this context, Shotter and Tsoukas (2014b; 381) quote from NE 1142a27-1142a29 to support the argument that phronesis as wisdom is practiced in particular circumstances of immanent contexts, and that the chief task of organizational decision-makers is to grasp the generalized features of immediate situations. At this point, their reading of Aristotle is related primarily to the passage where the internal qualities of practical wisdom are contrasted with political leadership, instead of the broader discussions in NE on the role of the understanding of the particularities in contrast to the functions of philosophical wisdom.

Elsewhere, Shotter and Tsoukas (2014a; 233) give more prominence to the cosmological backdrop of virtues necessary to furnish the ethical soundness of actions taken. They note that in order for action to be virtuous, the subject needs to contemplate and internalize a broader ethical reality within which the intended good actions are to be embedded. Here, the strictly immanentist understanding of the particularistic conception of wise action is complemented with a more transcendental orientation towards the metaphysical base of virtues as derived from rational reasoning and deliberation (Moss 2014). Moral virtues necessary for ethically sustainable action require intellectual preparations along with the purely calculative processes of practical deliberation.

Overall, however, Shotter and Tsoukas (2014a, 2014b) interpret Aristotle's work on wisdom as advocating a view that prioritizes an ethically sound sensing of the salient features of each particular situation. They argue that virtues are formed in emotional processes that build a habituated sense of the good, thus guiding practical judgements towards a specific range of action corresponding with the ethical order. Furthermore, Shotter and Tsoukas underline in their exposition that as emerging affect-laden dispositions, moral virtues are different from universal rules emphasized in the rationalistic approaches to managerial judgement. Virtues are not formed in the philosophical contemplations associated with theoretical wisdom.

\section{Situating the Exemplary Interpretations of Management Wisdom}

The different appropriations of Aristotle's conception of wisdom - Aquinian, Heideggerian and Gadamerian - provide us with a usable comparative framework to situate the different understandings of wisdom inherent in the three representative samples of management theory. Equipped with a sensitivity to the genealogical variety of Aristotelian appropriations, this section aims to situate the three exemplary management theory contributions vis-à-vis the different interpretations of Aristotelian phronesis and wisdom.

Flyvbjerg (2004) defends a strong version of a particularistic and praxis-oriented reading of Aristotle's conception of wisdom. His version of phronesis is based on the idea that a viable programme of practical wisdom needs to orient itself towards the variable contexts of immanent situations and everyday occurrences. The focus on praxis is supported in Flyvbjerg's work by the introduction of philosophical insights from Foucault and Nietzsche to complement Aristotle. Foucault's Nietzschean appropriation of will-to-power in the form of 
an analysis of relational mechanisms and practices of productive power (Foucault 1982; Deleuze 1998) is welcomed by Flyvbjerg as a valuable extension of Aristotle's engagement with phronesis, clarifying the ways in which subjects are caught up in the nexuses of powerknowledge within the immanent contexts of sociality. Flyvbjerg's introduction of Foucault amplifies the reading of NE as a treatise in the situated nature of prudent judgment within the confines of particular situations and events. The Nietzschean ontology of sociality as a relational assemblage of primordial forces adopted by Foucault provides a resource to further bracket the role of theoretical wisdom in the ensuing understanding of prudence as a predominantly particularist endeavour (Falzon 2006).

In this sense, Flyvbjerg's (2004) Foucauldian appropriation of Aristotle places his embracing of wisdom adjacent to Heidegger's approach, where practical phronesis is largely separated from the metaphysical considerations associated with sophia. Wisdom is conceptualized as ethically valorised coping within the particularist contexts of the contemporary sociocultural condition. For Flyvbjerg, Foucault provides a valuable perspective on the role of power relations in the absorbed coping of the particularities of contingent situations. However, it could be argued that the insistence on the primacy of practical coping as attested by Heidegger in his existential phenomenology is also broadly shared by Flyvbjerg in his Aristotelian-Foucauldian account of phronesis.

Likewise, Shotter and Tsoukas (2014a, 2014b) develop a reading of wisdom that ostensibly prioritizes the role of the particulars and practical contexts. Their work extends Aristotle's programme in NE with insights from late Wittgenstein, pragmatism and phenomenology, to depict a picture of wisdom as a gradual process of coming to see the novel features of emerging situations in a broader general context. The dynamics of learning to cope with the shifting particulars is enmeshed with emotional reflections that mediate the dialectical process of contrasting the new particulars with experiences of exemplary memories and embodied intuitions about moral maxims.

The incorporation of phenomenological perspectives on the embodied sense-making underlying the tacit knowledge developed and developing in the face of novel organizational situations guides Shotter and Tsoukas (2014a, 2014b) into a terrain that gives prominence to a process of the fusing of the generalized and locally experienced horizons. New occasions encountered are experienced as unique instances of tacitly recognizable patterns, while at the same time the prevailing understandings are being revised in light of the original features of the emerging situational occurrences.

Overall, then, Shotter and Tsoukas's (2014a, 2014b) perspective on wisdom as phronesis bears a resemblance to Gadamer's (1960) hermeneutic re-reading of phronesis and sophia. As noted, wisdom is conceptualized by Gadamer as a dialectic between theoretical and practical knowledges performed within the hermeneutic circle by way of juxtaposing the particular features of unique situations with the repertoires of pre-understanding contained in the prevailing discourses of wisdom.

For Shotter and Tsoukas (2014a, 2014b), wisdom is conceptualized as practical coping in a milieu, where actors are not exhaustively absorbed into Heideggerian contexts of practical activity but are instead engaged in hermeneutic processes of embodied sense-making consisting of dialectical movements between particulars and universals within the communicative discourses. Wisdom involves the heuristic search for general frames within which particulars could make sense, as well as a synchronous process of deductively testing the validity of established pre-understandings against the broader meanings of experienced situations. In this re-conceptualization of Aristotelian wisdom, the domain of practical action is 
broadened from the immediate contexts of local events to the hermeneutic praxis of evolving understandings, where historically circumscribed traditions replace the role of theoretical knowledge as a realm of transcendental truth or first principles.

Nonaka and Toyama (2007), on the other hand, display an apparent appreciation of both sophia and phronesis by acknowledging the role of transcendental moral truths alongside the importance of the salient aspects of situated particularities. They argue that the recognition of the good requires a solid philosophical foundation provided by the ideals of truth, beauty and goodness. This would suggest that they are following a dualist interpretation that emphasizes the roles of both theoretical and practical wisdom in the pursuit of sound prudence, and that they are even to some extent paying attention to the transcendental nature of the good as a philosophical ideal consistent with an Aquinian view of the metaphysical sources of theoretical wisdom.

At a closer reading, however, the framework of Nonaka and Toyama (2007) can be seen as incorporating other significant features that shift the understanding of wisdom away from the dualistic view. Nonaka and Toyama (2007) highlight in their discussion the importance of intuiting the generalized features of particular situations as a method of grasping the universal conditions behind immediate situations. Here, the inductive method takes over from a more deductive reasoning that was originally promoted by Aristotle in the form of the use of universal propositions in the development of the major premise in the practical syllogism. Furthermore, Nonaka and Toyama (2007) underscore that the conventional truths need to be sensed against the realities of particular situations; thus, opening an avenue for a reciprocal process of traversing back and forth between the universal ideas and local experiences.

In essence, Nonaka and Toyama (2007) seem to develop a multifaceted approach to organizational wisdom that fuses the discussion of the role of the good with a Gadamerian appropriation of phronesis as a process of hermeneutic sense making. The notion of the transcendental sources of the good resonates with the elucidations of Aquinas. The hermeneutic aspect, in turn, is illuminated by their focus on the simultaneous considerations of the universal-in-the particular and the particular-in-the universal, accomplished through intuiting the essence behind the particularity of the situation, while at the same time testing the validity of the universal ideals and theories in relation to experiences of the local. A hermeneutic disposition is also evident in their suggestion that managerial insights into universalized particulars are thought to be disseminated and cultivated through the use of metaphorical language and narratives in the communicative space of organizational discourse.

\section{Conclusions: The Challenges of the Aristotelian Theory of Wisdom in Contemporary Philosophy of Management}

Management theory has adopted Aristotle's philosophy in its pursuit of understanding management wisdom as phronesis, or practical wisdom. Yet, as we have demonstrated in this article, Aristotle's (2009) position in NE can be understood as incorporating both practical and theoretical wisdom in the overall appraisal of the nature of wisdom. Aristotle's ultimate position has remained, however, ambiguous, giving rise to different interpretations of his work on intellectual virtue (Baehr 2012). Furthermore, his complex discussion on theoretical and practical wisdom has prompted various philosophical appropriations of sophia and phronesis, the reworkings of Aquinas, Heidegger and Gadamer being among the most notable later elucidations. An analysis of selected management theory contributions against different 
appropriations of Aristotle's work on phronesis and sophia, has provided some initial steps towards a better comprehension of the ways in which the Aristotelian philosophy of wisdom is being adopted in contemporary philosophy of management.

Based on our re-reading of the texts, it is the existential-hermeneutic reworking of Aristotelian wisdom as phronesis that seems to inform the representative samples of management theory contributions. Flyvbjerg's (2004) work is closer to a Heideggerian interpretation of wisdom as practical coping and transgression in immanent contexts of sociality and power, while Shotter and Tsoukas's (2014a, 2014b) treatment displays traces of Gadamerian thinking alongside an emphasis on the embeddedness of managerial reflection and judgement in situated practices. Nonaka and Toyama's (2007) contribution differs from the others, insofar as it features references to aspects of theoretical wisdom reminiscent of the dualist interpretation and even the re-working of Aquinas. Nevertheless, their position also follows a largely Gadamerian approach as they simultaneously highlight the importance of dialogically traversing between the lessons gained from local experiences and the more theoretical insights of universal knowledge.

Central for our argument is the observation that the Heideggerian-Gadamerian-inspired appropriation of Aristotle's work is not the only authoritative interpretation of the Aristotelian conception of wisdom, and that the broader philosophical debate suggests that in order to fully appreciate Aristotle's thinking in NE, the relationship between theoretical and practical knowledge needs to be examined and discussed more closely (Baehr 2012; Reeve 2006; Natali 2014). In this context, Aquinas has been introduced as a developer of a dualist interpretation. Approaching the Aristotelian notion of wisdom as dedicated purely to the practical intellect narrows the discussion on the nature of (organizational) wisdom within an Aristotelian framework in ways that do not give full credit to the complexity of Aristotle's philosophy of intellectual virtues.

A central argument among the proponents of a particularist conception of wisdom is the notion that universal rules inherent in theoretical knowledge cannot provide useful guides for prudent conduct in the shifting situations of organizational life (e.g. Flyvbjerg 2004; Shotter and Tsoukas 2014a). However, this view is based on a somewhat erroneous or deficient understanding of Aristotle's own discussion of theoretical wisdom. Aristotle (2009) defined theoretical wisdom as a combination of scientific knowledge and intuitive reason that together constitute an awareness of the metaphysical first principles in their empirical manifestations. Universal truths are grasped inductively and intuitively, nonetheless they do not constitute uniform rules in the way the proponents of phronetic Aristotelianism suggest. Aristotle was a theory universalist, not a rule universalist (Vaccarezza 2018).

Furthermore, if the activity of theoretical knowledge, theoria (Nightingale 2004), is understood generally as the natural inclination associated with the function of human beings, the theoretical component of intellectual virtues can be extended beyond its restricted place as the abstract contemplation of higher truths. Taking the cue from the Book X of NE, it is possible to develop an argument that all the intellectual virtues Aristotle discusses are theoretical activities of some sort (Roochnik 2009). Sophia is then seen as the highest form of theoretical activity, but at the same time, phronesis can be understood as a supplementary intellectual exercise employing the rational faculty of the truth-seeking mind. If the ability to grasp metaphysical truths is what differentiates humans from other animals (Nagel 1972), then it is the mobilization of this nature that characterizes our ultimate telos. Practical wisdom can be envisioned as the activity of using what is most esteemed in us to find the best ways to act in the immanent world (Reeve 2006). Phronesis is theoretical. 
These remarks demonstrate how, within the range of different interpretations of theoretical and practical wisdom, Aristotle's work can be read in various different ways that lead to notably dissimilar conclusions regarding the adapted conception of wisdom in the philosophy of management. This is not to suggest that a phronetic interpretation of wisdom is in itself faulty or poorly conceived. Rather, it is to note that any conception of wisdom relying on Aristotle's authority needs to be conscious of the ambiguity involved with Aristotle's examination of intellectual virtues. Claiming a particularistic conception of wisdom based on Aristotelian phronesis might be laden with presuppositions that are not directly derivative of Aristotle's complex discussions or from his overall philosophical outlook. In a sense, it would be more accurate to explain that the adapted understanding of management wisdom is a NeoAristotelian appropriation reflecting the post-metaphysical turn inherent in the works of late modern philosophers such as Heidegger and Gadamer. The paucity of reflection on the nuances and contradictions of Aristotle's thinking in studies of management wisdom nonetheless raises more general questions concerning the philosophical literacy or proficiency of management theorizing (cf. Crockett 2008). However, fleshing out these vexing issues must remain a subject for further investigations.

Funding Open access funding provided by Aalto University. The Wihuri Foundation (Finland) has supported research work for this paper.

\section{Declarations}

Conflict of Interest No conflicts of interest.

Open Access This article is licensed under a Creative Commons Attribution 4.0 International License, which permits use, sharing, adaptation, distribution and reproduction in any medium or format, as long as you give appropriate credit to the original author(s) and the source, provide a link to the Creative Commons licence, and indicate if changes were made. The images or other third party material in this article are included in the article's Creative Commons licence, unless indicated otherwise in a credit line to the material. If material is not included in the article's Creative Commons licence and your intended use is not permitted by statutory regulation or exceeds the permitted use, you will need to obtain permission directly from the copyright holder. To view a copy of this licence, visit http://creativecommons.org/licenses/by/4.0/.

\section{References}

Ames, Maria Clara Figueiredo Dalla Costa, Maurício Custódio Serafim, and Marcello Beckert Zappellini. 2020. Phronesis in administration and organizations: A literature review and future research agenda. Business Ethics: A European Review 29 (S1): 65-83. https://doi.org/10.1111/beer.12296.

Antonacopoulou, Elena P. 2010. Making the business school more 'critical': Reflexive critique based on phronesis as a foundation for impact. British Journal of Management 21: s6-s25.

Aquinas, Thomas. 1920. Summa Theologiae, translated by the fathers of the English Dominican Province, London: Oates and Washbourne.

Aristotle. 2009. The Nicomachean Ethics (Oxford World's classics). Translated by David Ross, Revised with an introduction and notes by Lesley Brown. Oxford University Press Oxford, UK.

Bachmann, Claudius, André Habisch, and Claus Dierksmeier. 2018. Practical wisdom: Management's no longer forgotten virtue. Journal of Business Ethics 153 (1): 147-165.

Backman, Jussi. 2015. Hermeneutics and the Ancient Philosophical Legacy. In A Companion to Hermeneutics, eds N. Keane and C. Lawn, 22-33. Malden, MA: John Wiley \& Sons.

Baehr, Jason. 2012. Two types of wisdom. Acta Analytica 27 (2): 81-97. 
Baker, Samuel. 2017.The metaphysics of goodness in the ethics of Aristotle. Philosophical Studies 174 (7): 1839-1856.

Beadle, Ron. 2002. The misappropriation of MacIntyre. Philosophy of Management 2: 45-54. https://doi.org/10. 5840/pom 2002226.

Cammack, Daniela. 2013. Aristotle's denial of deliberation about ends. Polis: The Journal for Ancient Greek and Roman Political Thought 30 (2): 228-250.

Cooper, John M. 1969. Intellectualism and practical reasoning in Aristotle's moral philosophy. The Society for Ancient Greek Philosophy Newsletter. 25. https://orb.binghamton.edu/cgi/viewcontent.cgi?article=1024\&context=sagp

Crockett, Carter. 2008. MacIntyre. Philosophy of Management 7: 45-66. https://doi.org/10.5840/pom2008716.

Dancy, Jonathan. 2004. Ethics without principles. Oxford: Oxford University Press. https://doi.org/10.1093/ 0199270023.001 .0001 .

Deleuze, Gilles. 1998. Foucault. London: The Athlone Press.

Duvenage, Pieter. 2015. Practical wisdom (Phronesis) and hermeneutical politics. Phronimon 16 (1): 77-96.

Eh, Edmond. 2017. Wisdom in Aristotle and Aquinas: From metaphysics to mysticism. Existenz 12 (2): 19-24.

Falzon, Chris. 2006. Foucault and social dialogue: Beyond fragmentation. Routledge.

Flyvbjerg, Bent. 2002. Bringing Power to Planning Research: One Researcher's Praxis Story. Journal of Planning Education and Research 21 (4): 353-366. https://doi.org/10.1177/0739456X0202100401.

Flyvbjerg, Bent. 2004. Phronetic planning research: Theoretical and methodological reflections. Planning Theory \& Practice 5 (3): 283-306.

Foucault, Michel. 1982. The subject and power. Critical Inquiry 8 (4): 777-795.

Gadamer, Hans-Georg. 1960. Wahrheit und Methode. Tübingen: JCR Mohr.

Grint, Keith. 2007. Learning to lead: Can Aristotle help us find the road to wisdom? Leadership 3 (2): 231-246.

Hartman, Edwin M. 2015. Rationality in management theory and practice: An Aristotelian perspective. Philosophy of Management 14 (1): 5-16. https://doi.org/10.1007/s40926-015-0003-9.

Heidegger, Martin. 1927. Sein und Zeit. Tübingen: Max Niemeyer Verlag.

Kessler, Eric H., and James R. Bailey (ed.). 2007. Handbook of Organizational and Managerial Wisdom. Sage Publications. https://doi.org/10.4135/9781412982726.

Kuepers, Wendelin M., and David Pauleen. 2015. Learning wisdom: Embodied and artful approaches to management education. Scandinavian Journal of Management 31 (4): 493-500.

Küpers, Wendelin, and Matt Statler. 2008. Practically wise leadership: Toward an integral understanding. Culture and Organization 14 (4): 379-400.

Leibowitz, Uri D. 2013. Particularism in Aristotle's Nicomachean ethics. Journal of Moral Philosophy 10 (2): 121-147. https://doi.org/10.1163/174552412X628904.

Liu, Wei. 2011. An all-inclusive interpretation of Aristotle's contemplative life. Sophia 50 (1): 57-71.

Long, Christopher P. 2002. The ontological reappropriation of phronēsis. Continental Philosophy Review 35 (1): 35-60.

McDowell, John. 2014. Virtue and reason. The Monist 62 (3): 331-350. https://doi.org/10.5840/ monist197962319.

McKenna, Bernard, David Rooney, and Jay Hays. 2011. Wisdom and the good life. Philosophy of Management 10 (1): $1-7$.

McKenna, Bernard, David Rooney, and Amy L Kenworthy. 2013. Introduction: Wisdom and management - A guest-edited special collection of resource reviews for management educators. Academy of Management Learning and Education, 12(2), 306-311.

Moss, Jessica. 2014. Right reason in Plato and Aristotle: On the meaning of logos. Phronesis 59 (3): 181-230. https://doi.org/10.1163/15685284-12341266.

Nagel, Thomas. 1972. Aristotle on Eudaimonia. Phronesis 17 (3): 252-259.

Natali, Carlo. 2014. The book on wisdom. In The Cambridge Companion to Aristotle's Nicomachean Ethics, edited by Ronald Polansky, 180-202. Cambridge: Cambridge University Press. https://doi.org/10.1017/ CCO9781139022484.009.

Nightingale, Andrea Wilson. 2004. Spectacles of truth in classical Greek Philosophy: Theoria in Its Cultural Context. Cambridge, UK: Cambridge University Press.

Nonaka, Ikujiro, and Ryoko Toyama. 2007. Strategic management as distributed practical wisdom (Phronesis). Industrial and Corporate Change 16: 371-394. https://doi.org/10.1093/icc/dtm014.

Nonaka, Ikujiro, Robert Chia, Robin Holt, and Vesa Peltokorpi. 2014. Wisdom, management and organization. Management Learning 45 (4): 365-376. https://doi.org/10.1177/1350507614542901.

Reeve, C D C. 2006. Aristotle on the Virtues of Thought. In The Blackwell Guide to Aristotle's Nicomachean Ethics, Ed. Richard Kraut, 198-217. London: Blackwell.

Reeve, C.D.C. 2013. Aristotle on practical wisdom: Nicomachean ethics VI. Cambridge, MA: Harvard University Press.

Roochnik, D. 2009. What is Theoria? Nicomachean ethics book 10. 7-8. Classic Philology 104 (1): 69-82. 
Rorty, Amelie O. 1978. The place of contemplation in Aristotle's Nicomachean ethics. Mind 87(3): 343-358. Schwartz, B. 2011. Practical wisdom and organizations. Research in Organizational Behavior 31: 3-23.

Shotter, John, and Haridimos Tsoukas. 2014a. Performing Phronesis: On the way to engaged judgment. Management Learning 45 (4): 377-396. https://doi.org/10.1177/1350507614541196.

Shotter, John, and Haridimos Tsoukas. 2014b. In search of Phronesis: Leadership and the art of judgment. Academy of Management Learning \& Education 13 (2): 224-243 http://www.jstor.org/stable/43698354.

Sorabji, Richard. 1980. Aristotle on the role of intellect in virtue. In Essays on Aristotle's ethics, ed. Amélie Oksenberg Rorty, 201-220. Berkely: University of California Press. https://doi.org/10.1525/ 9780520340985-015.

Thanassas, Panagiotis. 2012. 'Phronesis vs. Sophia:' On Heidegger's ambivalent Aristotelianism. The Review of Metaphysics 66 (1): 31-59 http://www.jstor.org/stable/41635551.

Vaccarezza, Silvia, and Maria. 2018. An eye on particulars with the end in sight: An account of Aristotelian Phronesis. Metaphilosophy 49 (3): 246-261. https://doi.org/10.1111/meta.12296.

Yang, Shih-ying. 2011. Wisdom displayed through leadership: Exploring leadership-related wisdom. Leadership Quarterly 22: 616-632. https://doi.org/10.1016/j.leaqua.2011.05.004.

Publisher's Note Springer Nature remains neutral with regard to jurisdictional claims in published maps and institutional affiliations.

Dr. Tuomo Peltonen is Adjunct Professor of Organizations and Management at Aalto University School of Business, Finland. Previously, he was a professor of management at Universities of Turku, Tampere and Oulu. His recent interests include wisdom, legitimate authority and cooperatives. Professor Peltonen has published 40 articles and eight books. 